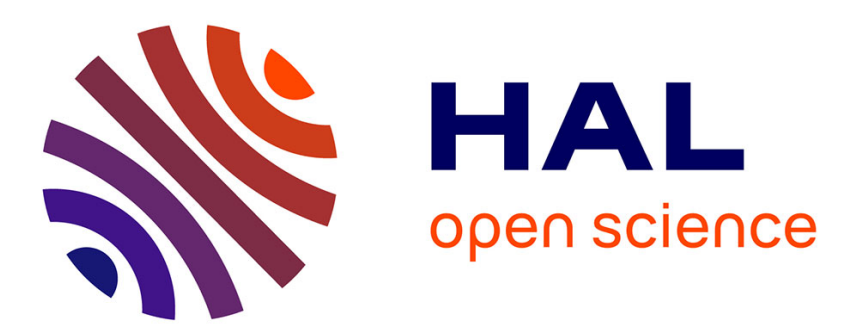

\title{
Quantifying the relationship linking the community-weighted means of plant traits and soil fertility
}

Laurent Daou, Garnier Eric, Bill Shipley

\section{- To cite this version:}

Laurent Daou, Garnier Eric, Bill Shipley. Quantifying the relationship linking the community-weighted means of plant traits and soil fertility. Ecology, 2021, 102 (9), pp.e03454. 10.1002/ecy.3454 . hal03422748

\section{HAL Id: hal-03422748 \\ https://hal.science/hal-03422748}

Submitted on 9 Nov 2021

HAL is a multi-disciplinary open access archive for the deposit and dissemination of scientific research documents, whether they are published or not. The documents may come from teaching and research institutions in France or abroad, or from public or private research centers.
L'archive ouverte pluridisciplinaire HAL, est destinée au dépôt et à la diffusion de documents scientifiques de niveau recherche, publiés ou non, émanant des établissements d'enseignement et de recherche français ou étrangers, des laboratoires publics ou privés. 
MR. LAURENT DAOU (Orcid ID : 0000-0002-6724-4769)

PROF. BILL SHIPLEY (Orcid ID : 0000-0002-7026-3880)

Article type : Articles

Journal: Ecology

Manuscript type: Articles

Running Head: Fertility-plant traits relationship

Quantifying the relationship linking the community weighted means of plant traits and soil fertility

Laurent Daou ${ }^{1}$, Éric Garnier ${ }^{2}$, Bill Shipley ${ }^{1 *}$

${ }^{1}$ Laboratoire d'Écologie Fonctionnelle, Département de biologie, Université de Sherbrooke, Sherbrooke (QC) Canada J1K 2R1

${ }^{2}$ Centre d'Écologie Fonctionnelle et Evolutive (CEFE), Univ Montpellier, CNRS, EPHE, IRD, Univ Paul Valéry Montpellier 3, Montpellier, France

*Author for correspondence. E-mail: Bill.Shipley@USherbrooke.ca

This article has been accepted for publication and undergone full peer review but has not been through the copyediting, typesetting, pagination and proofreading process, which may lead to differences between this version and the Version of Record. Please cite this article as doi: $\underline{10.1002 / \mathrm{ECY} .3454}$

This article is protected by copyright. All rights reserved 
Abstract. Is it possible to generalize relationships between certain plant traits and soil fertility? In particular, are there quantitative relationships between community weighted mean (CWM) trait values of leaf dry matter content (LDMC), specific leaf area (SLA), plant height and Grime's CSR strategy scores and the generalized soil fertility, $\mathrm{F}_{\mathrm{G}}$ (i.e. the capacity of a soil to produce biomass when all non-soil variables are held constant) that are generalizable across different species assemblages and geographical areas? We assessed $\mathrm{F}_{\mathrm{G}}$ in 21 sites in southern Quebec and 7 sites in southern France using a previously published method based on structural equation modelling. We then determined the CWM values of LDMC, SLA, plant height and CSR scores in the 21 Quebec sites to obtain quantitative relationships between $\mathrm{F}_{\mathrm{G}}$ and these $\mathrm{CWM}$ traits. Using these relationships, we independently tested the generality of the trait-fertility relationships using data from French sites. The relationships between $\mathrm{F}_{\mathrm{G}}$ and the $\mathrm{CWM}$ traits were nonlinear but displayed the expected qualitative trends as reported in the literature. In particular, the S-score and CWM LDMC decreased with increasing soil fertility while the R-score and CWM SLA increased. CWM traits were more strongly correlated to measures of $F_{G}\left(r^{2}\right.$ up to 0.48$)$ than to measures of other soil characteristics ( $r^{2}$ up to 0.17 for nitrogen flux). Importantly, the independently tested French $F_{G}-$ trait relationships showed no significant deviations from these quantitative relationships. Further investigation is necessary to confirm if the same trend applies to other regions and or ecosystems.

Key-words: community weighted functional traits; Grime's CSR strategies; leaf dry matter content; plant height; SEM; soil fertility; specific leaf area; Structural equation modelling.

This article is protected by copyright. All rights reserved 


\section{Introduction}

It has often been hypothesized that there exists a systematic relationship between differences in the net primary productivity (NPP) of sites (the inverse of "stress"; Grime 1979) and communityweighted means (CWM) of plant functional traits such as the maximum relative growth rate (RGR), specific leaf area (SLA), leaf dry matter content (LDMC) and leaf area (LA) (Vile et al. 2006; Ordoñez et al. 2009; Hodgson et al. 2011; Liu et al. 2012; Tab. 4.1 in Garnier et al. 2016 p75). The NPP of a site is determined both by soil properties we call here "soil fertility" (nutrient fluxes and pools, soil structure, soil microflora and fauna, etc.) and non-soil properties (water inputs, temperature, vegetation composition etc.). Grime's $(1979,2001)$ community level hypothesis, with respect to soil properties, would state that there exists a quantitative relationship that is generalizable across different taxonomic groups and geographical locations between the level of soil fertility at a site and the CWM values of the relevant traits (Garnier et al. 2004). If correct, then it would be possible to predict the CWM trait values of new sites after measuring their levels of soil fertility. In this paper we test this community level hypothesis, which is a foundational claim of trait-based ecology. If the evidence for it is weak or lacking, then this represents an important "loose foundation stone" (Shipley et al. 2016) that must either be reinforced or replaced. Since this hypothesis is commonly assumed in the ecological literature (for example, Vitousek et al. 1992; Ordoñez et al. 2009), it might seem that it has strong empirical support. In fact, it has never been properly tested because no study has actually included each of the three necessary steps required for such a test: the measurement, in different sites, of the productive capacity of different soils when non-soil properties are held constant (soil fertility); the quantification of the relationship between soil fertility and the relevant CWM of traits; the measurement of the soil fertility and CWM trait values of new sites that were not included in the original predictive relationship and a demonstration that the CWM trait values of these new sites are consistent with the original quantitative relationship.

Several studies in plant functional ecology have shown that, when comparing species typical of sites with qualitatively high or low NPP, these species differ in terms of values of certain traits related to resource capture and retention (Grime, 1977; 2001; Chapin III, 1980; Tilman, 1988; Chapin III et al., 1993; Garnier et al. 2016). However, qualitative comparisons between sites having different NPP cannot be used to claim that there is a predictable quantitative relationship between the two. Of the

This article is protected by copyright. All rights reserved 
publications that have related plant traits to independently measured components of soil fertility, the strength of the correlations are surprisingly weak. For instance, Ordoñez et al. (2009), in a global study on 474 species in 99 sites found that only 22-23\% of an integrated leaf economy measure was explained by soil variables alone. Fujita et al. (2013) in a study of 134 communities of grasslands explained only $33 \%$ of the between-site variations of leaf nitrogen content when using all the measures of fertility together. Since none of these studies have actually measured soil fertility (i.e. the capacity of a soil to increase or decrease plant growth, when non-soil causes are constant), but only certain causes of it, it is possible that these weak and variable relationships are due to poor measures of soil fertility (Ordoñez et al. 2010). Typically, these studies do not directly measure either NPP or any other measure of plant production; rather, they measure soil properties that are (partial) causes of productivity. Many of the methods employed were developed for agricultural purposes in particular soils and climates and were tuned for specific species rather than for use in broad interspecific comparisons or for community-level comparisons. They typically concentrate on the causes of soil fertility (concentrations and or fluxes of soil chemical nutrients) rather than the effects of soil fertility (the rate of plant biomass production). However, plant growth in different soils (or even the same soil at different times) can be limited by different causes (Chapin III et al. 1986; Fay et al. 2015). Because of this, there is no general way of translating between levels of different limiting nutrients that result in the same level of soil fertility and so it is impossible to quantitatively compare different soils in terms of their "fertility" using these methods. Furthermore, since the links between soil nutrients and plant productivity are species dependent, none of these methods can be applied at the scale of entire plant communities. In fact, the notion of a limiting nutrient does not necessarily apply at the scale of communities since different species in a community can potentially be limited by different nutrient ratios and so the biomass production of the community is not only a consequence of soil nutrient fluxes but also of the species composition (Chapin III et al. 1986, Danger et al. 2008). Testing the hypothesis of this paper requires a concept of plant "fertility" that is applicable at the scale of entire plant communities and that produces common measurement units when measured in soils whose causes of soil fertility are different.

Daou \& Shipley $(2019 ; 2020)$ produced such a method. Briefly, this method consists of growing 4 different phytometer species (Festuca rubra, Trifolium pratense, Triticum aestivum and Arabidopsis

This article is protected by copyright. All rights reserved 
thaliana) differing widely in their resource ecology, in sieved soils or intact soil cubes under controlled conditions of temperature, irradiance and water inputs. Using structural equation modeling, Daou \& Shipley (2019) showed that, although the RGR values and final biomass of these species differed greatly across 76 soils from southern Quebec (Canada) and between species, they were all strongly correlated. Furthermore, the RGR values of the different species became mutually independent upon conditioning on a single latent variable using a structural equation model (a measurement model), meaning that there was a single underlying latent cause that they called "generalized soil fertility" $\left(\mathrm{F}_{\mathrm{G}}\right) . \mathrm{F}_{\mathrm{G}}$ is therefore a measure of the capacity of a soil to produce plant biomass when non-soil causes of NPP are held constant. $\mathrm{F}_{\mathrm{G}}$ was more strongly correlated with the aboveground NPP of the natural communities growing on these sites, when grown in a common garden, than any of several soil properties, including N, P and K nutrient fluxes, used alone or in combination. Because $\mathrm{F}_{\mathrm{G}}$ is based on measures of plant growth and not on soil characteristics, these values can be compared across sites even if the causes of the soil fertility (i.e. the soil characteristics) differ or even if they are not measured or known. Thus, the objective of this paper is to use this method to measure the soil fertility and provide the first clear empirical test of the community-level hypothesis.

\section{Materials and methods}

Measurement of generalized fertility: The steps of analysis are shown graphically in Appendix S1: Fig. S1. The original model for $\mathrm{F}_{\mathrm{G}}$ (Daou \& Shipley 2019) was based on 76 sites, from which Daou \& Shipley (2020) selected a sub-sample of 26 sites. From these 26 sites, they developed four modifications of the original equations for $\mathrm{F}_{\mathrm{G}}$ from Daou \& Shipley (2019) to be used for either sieved soil ("sieved") or intact soil cores ("intact"), and for either relative growth rate ("RGR") or for ln-transformed final biomass ("BM") as the measure of plant productivity. These four estimates of $\mathrm{F}_{\mathrm{G}}$, published in Daou \& Shipley (2020), are used here and are called " $F_{G}$ RGR intact", " $F_{G}$ BM intact", " $F_{G}$ RGR sieved", and " $F_{G} B M$ sieved". More details about sites coordinates and descriptions are available in Daou and Shipley $(2019,2020)$.

Testing the model in Quebec

This article is protected by copyright. All rights reserved 
Vegetation survey: We selected 21 of the 26 grassland sites used in Daou \& Shipley (2020) and returned to the exact same locations from which the soils were originally collected two years later; five of the original sites had been subsequently disturbed and so were excluded (coordinates and description of soil origins of sites are available in Appendix S1: Table S3). A single $50 \mathrm{~cm}$ x $50 \mathrm{~cm}$ quadrat was randomly placed at each site. Within each quadrat, the aboveground biomass of all plants present in two $10 \mathrm{~cm}$ bands along the quadrat were collected and separated by species. Biomass was dried at $60{ }^{\circ} \mathrm{C}$ for at least 2 days. A total of 91 species was found in these 21 sites. The dried biomass provided estimates of the relative abundance of each species at each site. The remaining aboveground biomass in the quadrat was dried at $60{ }^{\circ} \mathrm{C}$ for 2 days and weighed.

Measurement of Plant traits: For each species, five ramets were cut at ground level. The total height $(\mathrm{H})$ of the vegetative tissues (the stems were cut and straightened) was recorded on each of these five individuals as a measure of the plant height. Stems were placed in moist paper and kept in coolers for up to 8 hours before returning to the lab. Upon arrival, an intact leaf of each ramet was cut under water and left to respire with its petiole in water $12 \mathrm{~h}$ in the dark. This resulted in leaves at full turgidity and without non-structural carbohydrates (Garnier et al. 2001). Each leaf was then scanned to measure its area using the ImageJ program (https://imagej.net) and weighed. All the samples were dried at $60{ }^{\circ} \mathrm{C}$ for 2 days and weighed. The SLA of the leaf was calculated by taking the ratio of its projected surface $\left(\mathrm{mm}^{2}\right)$ of fresh leaf to its dried mass $(\mathrm{mg})$. The LDMC was calculated as the ratio dried mass:fresh mass. The CWM of each trait was calculated for each site as the sum of the product of the trait values of each species by its relative abundance (Garnier et al. 2004). These CWM values estimate the trait value of a "typical" individual calculated over all species in the site. Following Pierce et al. (2017), we then used the Stratefy spreadsheet (Pierce et al. 2013) to calculate Grime's CSR scores (competitors, stress tolerators, ruderals) for each site using the CWM values of leaf area, SLA and LDMC. The R and S dimensions are mostly determined by the tradeoff between SLA and LDMC while the $\mathrm{C}$ dimension is mostly determined by leaf area.

Independent test of the model in the French site

We employed a very different type of grassland in a long-term experimental site located in southern France on a limestone plateau (Larzac Causse) at the INRA La Fage experimental station $\left(43^{\circ} 55^{\prime} \mathrm{N}\right.$,

This article is protected by copyright. All rights reserved 
$3^{\circ} 05^{\prime} \mathrm{E}, 790 \mathrm{~m}$ a.s.l) having a typical Mediterranean climate with an average January temperature of 1 ${ }^{\circ} \mathrm{C}$, average August temperature of $19{ }^{\circ} \mathrm{C}$, and annual precipitation of $1070 \mathrm{~mm}$ (Bernard-Verdier et al. 2012). The data on species composition and CWM of SLA and LDMC were taken from (BernardVerdier et al. 2012, Chollet et al. 2014, Garnier et al. 2018). This is a subset of the traits measured in the Quebec data set. This site was traditionally grazed by sheep but has undergone experimental treatments since 1972 . We chose two paddocks that have been fertilized $(65 \mathrm{~kg} / \mathrm{ha}$ of N per year and $40 \mathrm{~kg}$ of $\mathrm{P}$ every 3 years) and intensely grazed since 1978. Three further paddocks received no fertilization and were less intensely grazed. Two final paddocks served as controls in which no fertilization was added and no sheep grazing was allowed. Using the same protocol as in Daou \& Shipley (2020), except that the growth experiment was conducted in a research greenhouse rather than in a growth room, we collected soil samples from the 7 paddocks and measured RGR and biomass of the same four phytometer species. Average temperatures during the growth experiment were $26^{\circ} \mathrm{C}$, which were approximately the same as in the original experiment of Daou \& Shipley (2020). Finally, using the RGR and biomass data of the four phytometers grown on the French soils and the prediction equations developed in Quebec (Daou and Shipley, 2020), we predicted $F_{G}$ values for each of the 7 French soils and for each of the four methods.

Soil measurements.

For soil samples from both Quebec and France, the flux of $\mathrm{NO}_{3}^{-}, \mathrm{P}$ and $\mathrm{K}$ and several other cations and anions were measured using PRS probes (WesternAg company) that were left $14 \mathrm{~d}$ in pots containing no plants but experiencing the same environmental conditions and water additions as for the growth measurements. Ion fluxes are expressed as $\mu \mathrm{g}$ per $10 \mathrm{~cm}^{2}$ for a 14-d period. The organic matter (OM) content was assessed by loss on ignition (Ben-Dor and Banin 1989).

Statistical analysis

We calculated the proportion of perennial plants at a site by scoring each species as 0 (annual) or 1 (perennial) and then calculating the community-weighted value of this trait ("perenniality", P). This was used as an indirect indicator of site disturbance. This gave a trait matrix for the Quebec data of 21 rows (sites) by eight columns (CWM values of C, S, R, SLA, LDMC, LA, H, P). We also had an environmental matrix for the Quebec data of 21 rows (sites) by eight soil properties ( $F_{G}$ RGR intact,

This article is protected by copyright. All rights reserved 
$\mathrm{F}_{\mathrm{G}} \mathrm{BM}$ intact, $\mathrm{F}_{\mathrm{G}}$ RGR sieved, $\mathrm{F}_{\mathrm{G}} \mathrm{BM}$ sieved, the flux of $\mathrm{N}, \mathrm{P}, \mathrm{K}$ and $\mathrm{OM}$ ). We used the R software version 2.13.2 (R Development Core Team, 2013) including the arm (Gelman et al. 2007), lavaan (Rosseel 2012), ade4 (Dray and Dufour 2007), lme4 (Bates et al. 2015) and mgcv (Wood et al. 2016) packages. To quantify the strength of the relationship between each of the seven community-weighted mean traits (Y) and each of the eight soil properties (X) using only the Quebec data, and without imposing any assumptions about the linearity of the relationship, we fitted a generalized additive model (GAM) of the form $\mathrm{Y} \sim \mathrm{s}(\mathrm{X})$. The strength of the relationship was quantified by the $\mathrm{r}^{2}$ of the model. The GAM was obtained via the gam() function (using thin plate regression splines) of the mgcv library of R. We limited the smoothing factor to $\mathrm{k} \leq 6$ because of the relatively small sample size (Wood 2017). In order to compare these nonlinear fits with a linear model, we also fitted the relationship using the gam function without a smoother and compared these fits using the anova function. We then projected the seven values of the French data (involving only the SLA and LDMC traits) onto the pre-existing relationships developed for the Quebec data. To test if the relationship between the trait and $\mathrm{F}_{\mathrm{G}}$ differed significantly in the French data relative to the Quebec data, we then added the French data to the Quebec data and included the origin (Quebec/France) as a factor in the gam model and tested the significance of this added factor.

\section{Results}

Relationships between community-weighted traits and soil fertility in the Quebec data

Table 1 summarizes the strength of the relationships between the community-weighted traits and generalized fertility $\left(\mathrm{F}_{\mathrm{G}}\right)$. as well as the various soil properties in the Quebec data. In almost every case, $\mathrm{F}_{\mathrm{G}}$ using sieved soil explained the highest proportion of variation in the community-weighted traits. $\mathrm{F}_{\mathrm{G}}$ using the intact soil cores almost always performed more poorly than the sieved soil in terms of the proportion of variation explained. Figure 1 and Figure 2 show the relationship between the $F_{G}$ values obtained in the sieved soil and the values of the community weighted SLA, LDMC, plant height and S and R scores. Community-weighted LDMC of the natural vegetation decreased and SLA increased with increasing $\mathrm{F}_{\mathrm{G}}$. The $\mathrm{S}$-score decreased, and the R-score increased, with increasing $\mathrm{F}_{\mathrm{G}}$. These relationships were all significantly nonlinear $(p<0.05)$. LA did not show any significant relationship with the soil properties. Vegetative height showed an unexpected relationship with $\mathrm{F}_{\mathrm{G}}$,

This article is protected by copyright. All rights reserved 
being highest at intermediate values. To test if this decrease in vegetative height at the highest $\mathrm{F}_{\mathrm{G}}$ values was due to an increase in disturbance, we also included the community-weighted proportion of perennials in the gam model. The original nonlinear relationship disappeared, and the resulting model showed a linearly increasing relationship for height, although this linear relationship did not reach statistical significance $(p=0.07)$. None of the nutrient flux measures $(\mathrm{N}, \mathrm{P}$ or $\mathrm{K})$ or the soil organic matter content showed strong relationships with any of the vegetation attributes (Table 1).

Generality of these trait - fertility relationships using the French data

Using the equations previously published by Daou and Shipley (2020), we then predicted the $\mathrm{F}_{\mathrm{G}}$ values for the French soils using independently measured RGR and biomass values of the phytometer species. We then projected these estimates of $\mathrm{F}_{\mathrm{G}}$, along with the measured community-weighted trait means, onto our previously derived relationships obtained from the Quebec data (coloured points in Figure 2 with the three colours indicating the three experimental treatments). The trait $-\mathrm{F}_{\mathrm{G}}$ relationship of the French data falls well within the scatter of the Quebec data. We then refit our generalized additive models after combining both Quebec and French data, and introducing a factor variable indicating the origin of the data. There was no statistical difference between the Quebec and French data since the origin of data did not significantly affected the relationships for either LDMC or SLA using $\mathrm{F}_{\mathrm{G}} \mathrm{BM}$ sieved ( $\mathrm{p}=0.25$ and $\mathrm{p}=0.85$ respectively), $\mathrm{F}_{\mathrm{G}}$ RGR sieved $(\mathrm{p}=0.57$ and $\mathrm{p}=$ $0.47), \mathrm{F}_{\mathrm{G}} \mathrm{BM}$ intact $(\mathrm{p}=0.39$ and $\mathrm{p}=0.90)$ or $\mathrm{F}_{\mathrm{G}} \mathrm{RGR}$ intact $(\mathrm{p}=0.26$ and $\mathrm{p}=0.99)$.

\section{Discussion}

Are there quantitative relationships between certain CWM trait values (LDMC, SLA, plant height and Grime's CSR strategy scores) and $\mathrm{F}_{\mathrm{G}}$ that are generalizable across different species assemblages and geographical areas? Because this is a foundational claim that has never been properly and critically tested, it is an important weakness of trait-based plant ecology. Certainly, the qualitative trait fertility relationships upon which this foundational claim is based are already well established, as synthesized in Tab. 4.1 of Garnier et al. (2016, p75). Several authors (Craine et al. 2001; Pontes et al. 2007; Ordoñez et al. 2009; Hodgson et al. 2011; Ordonez et Olff 2013; Jager et al. 2015; Laughlin et al. 2015; Maire et al. 2015; Louault et al. 2017) have shown that SLA increases, and LDMC decreases, with increasing levels of soil fertility, and our results agree with these qualitative claims.

This article is protected by copyright. All rights reserved 
Studies using more indirect measures of soil fertility, like Ellenberg N numbers (Shipley et al. 2017), have found the same trends. Pérez-Ramos et al. (2012) showed that the Nitrogen Nutrient Index (NNI; Lemaire and Gastal, 1997) was a good predictor of CWM SLA and LDMC in the French site. Our results agree with these previous qualitative patterns. Grime's S scores decreased, and R scores increased, with increasing levels of soil fertility in our study and these qualitative trends have now been experimentally demonstrated ( $\mathrm{Li}$ and Shipley 2017). However, the foundational claim is more than simply a qualitative one: if true, one should be able to quantitatively predict the trait values given the soil fertility in independent data. If we are ever able to quantitatively predict community assembly and structure from environmental data via models like CATS (Shipley, Garnier and Vile 2006; Shipley 2010; Warton 2015) or TRAITSPACE (Laughlin and Laughlin 2013), it is essential that such quantitative trait - environment relationships be demonstrated and generalized.

We found two important results. First, we observed quantitative, but often nonlinear, relationships between the community-weighted values of our traits and $\mathrm{F}_{\mathrm{G}}$ in the Quebec data. Secondly, independent data from a completely different geographical and climatic region and with an entirely different taxonomic composition, largely agreed with these relationships. These results confirm, for the first time, the foundational hypothesis that there exist quantitative relationships between $F_{G}$ and certain community-weighted traits that are generalizable across different taxonomic assemblages and geographical locations. Furthermore, the nonlinear nature of the relationships between $\mathrm{F}_{\mathrm{G}}$ and both LDMC and SLA suggest why existing qualitative trends are quite variable. Although the differences between studies in the strength of trait - environment relationships could be partly due to such nonlinearities, it would be impossible to know this without a quantification of soil fertility that is comparable across geographical regions. In fact, it would have been impossible to quantitatively compare the fertility of France and Quebec sites, and thus to know if their trait values exhibited the same quantitative patterns. This is because the measures of $\mathrm{NO}_{3}{ }^{-}, \mathrm{P}$ and $\mathrm{K}$ fluxes and soil organic matter had quite weak relationships to the traits. In particular, the use of the potential causes of $\mathrm{F}_{\mathrm{G}}(\mathrm{N}$, $\mathrm{P}$ and $\mathrm{K}$ flux, and $\mathrm{OM}$ ) were poorly correlated to our CWM traits even though previous authors had expected them to vary with soil fertility (Craine et al. 2001;Ordoñez et al. 2009; Liu et al. 2012; Jager et al. 2015). In the absence of experimental additions of specific soil nutrients, it is impossible to know which soil nutrients, or combinations of soil nutrients, actually limit plant productivity in either

This article is protected by copyright. All rights reserved 
the Quebec or France sites. It is possible (perhaps likely) that different nutrients were limiting in different sites, and even that different species in the same site might be limited by different nutrient ratios (Fay et al. 2015). Also, individual plants may have different nutrient limitations as they age, and they may have different responses to nutrient addition depending on the soil they are grown in (Brewster et al. 1976; Chapin III et al. 1986). By focusing on plant growth in these soils under controlled conditions, rather than fluxes of limiting nutrients, we could still provide quantitative comparisons of soil "fertility" across these soils in the absence of knowledge concerning limiting nutrients, although principal component analyses comparing ions fluxes are available in Appendix S1: Fig. S2). However, not all measures of soil "fertility" were equally useful (Table 1). The measures of $\mathrm{F}_{\mathrm{G}}$ obtained from the sieved soil were always superior to those obtained from intact soil cores. We have no explanation for this result. When comparing the sieved soils, the $\mathrm{F}_{\mathrm{G}}$ values obtained using ln(biomass) at a single harvest or using RGR over two harvests were very similar, but not identical. Which measure, a single harvest or RGR over two harvests, is a better indicator of $\mathrm{F}_{\mathrm{G}}$ ? The measure based on a single final aboveground biomass almost always explained a bit more of the variance in the community-weighted traits and this measure of $\mathrm{F}_{\mathrm{G}}$ also requires only half of the number of pots. However, the differences between the two measures are too small relative to the precision of our data for us to make a clear recommendation. Our measured correlations between traits and the underlying soil properties were comparable to those reported by others; our highest values were from soil nitrate flux vs. the $\mathrm{S}$ and $\mathrm{R}$ scores $\left(\mathrm{r}^{2}=0.17\right)$. Note that this was much lower than when soil fertility was measured via $\mathrm{F}_{\mathrm{G}}\left(\mathrm{r}^{2}=0.48\right)$. Pontes et al. (2007) reported a correlation between $\mathrm{N}$ supply and LDMC of 0.054 and 0.015 with SLA. Ordoñez et al. (2009) reported that C:N could explain up to $32-34 \%$ of SLA variation among sites. Liu et al. (2012) reported Pearson correlation r coefficients between SLA and the two principal axes of a PCA of 13 soil nutrients between -0.22 and 0.30 and no correlation for maximum height. Maire et al. (2015) reported a correlation of 0.06 and 0.04 between SLA and respectively soil $\mathrm{pH}$ and soil organic $\mathrm{C}$. This suggests that existing trait - fertility relationships underestimate the true strength of such relationships due to the way that they estimated soil fertility (Ordoñez et al. 2010). This emphasizes the advantage of using an integrated measure of soil "fertility" that reflects the actual plant responses to different soils, especially when extrapolating across very

This article is protected by copyright. All rights reserved 
different geographical regions, rather than concentrating on the complex interactions between the soil properties that potentially cause differences in soil fertility and that likely vary in space and time.

Predictive ability and generality of trait - soil fertility relationships

In Quebec, using $\mathrm{F}_{\mathrm{G}} \mathrm{BM}$ sieved, we explained a substantial amount of the variance (36 and 45\% respectively) in two key traits (SLA, LDMC) expected to vary predictably with increasing soil fertility (i.e. increasing for SLA and decreasing for LDMC). When we projected the independent data from France, the points fell well within the residual scatter of the Quebec data. Thus, these two trait $\mathrm{F}_{\mathrm{G}}$ relationships that were developed for the Quebec data were not only moderately predictive but also generalizable to a completely different geographical and climatic region, containing a completely different set of species with no statistical difference between the two data sets. Furthermore, the relatively small spatial extent of the Quebec vegetation samples that were used when estimating CWM trait values, which were dictated by the need to increase the number of sampled sites, meant that our estimates of these CWM trait values were likely rather variable and this would decrease the strength of the trait - fertility relationship. Such results are encouraging but can only be considered preliminary since this comparison is based on only seven sites within one small region of France. We encourage researchers to build on these quantitative comparisons in many different geographical regions.

If environmental factors other than soil fertility also filter a trait then one cannot expect a quantitative generalization across studies if such additional environmental factors are not taken into account. A possible example of this is the relationship between $\mathrm{F}_{\mathrm{G}}$ and plant height in the Quebec data, which was not what we expected given the existing literature. It was more weakly related to $F_{G}\left(r^{2}=0.16\right)$, and it showed a nonlinear relationship in which height increased with increasing $\mathrm{F}_{\mathrm{G}}$ up to a value of 0 and then decreased. Since reduction in height may be a response to increasing herbivory (Westoby 1999; Cingolani et al. 2005) or other forms of biomass destruction, we included the proportion of perennial species as an additional predictor, assuming that more recently disturbed vegetation would have a higher proportion of annual plants. Certainly, the $\mathrm{R}$ scores did increase rapidly at the highest values of $F_{G}$ and these $R$ (ruderal) scores should increase only when both fertility and disturbance increase together since both very stressed and very disturbed environments are not viable (Grime

This article is protected by copyright. All rights reserved 
1977). Indeed, the community-weighted height did increase linearly with increasing $F_{G}$ once this proxy for recent disturbances was introduced in the regression, but the proportion of the variance explained by $\mathrm{F}_{\mathrm{G}}$ remained low $\left(\mathrm{R}^{2}=0.074\right)$. Using the Quebec data, we explained $48 \%$ and $45 \%$ of Grime's S and R scores, respectively and both scores changed as expected, with S decreasing and R increasing with increasing $\mathrm{F}_{\mathrm{G}}$. This is consistent with Craine et al. (2001) who observed a decrease in abundance of high LDMC species as the soil fertility and the disturbance increased; with Fujita et al. (2013) that showed that, at the species level, the S-score decreased significantly with increasing availability of nutrients; and with the experimental evidence of Li \& Shipley (2017). Grime's C score did not show any significant change with $\mathrm{F}_{\mathrm{G}}$ in our data but this score was almost constant across our sites. Since these CSR scores, using Pierce's (2017) method, are defined by PCA axes based on LDMC, SLA and leaf area, and since the $\mathrm{C}$ score is primarily determined by differences in leaf area, these results simply reflect the underlying relationships involving LDMC and SLA, but do suggest that these $\mathrm{S}$ and $\mathrm{R}$ scores should be generalizable with respect to soil fertility. Our results therefore support Grime's original claim there exist quantitative relationships between typical (i.e CWM) trait values and soil fertility (the inverse of soil stress) that are generalizable across species assemblages and geographical areas, but with the added complication that these quantitative relationships can be strongly nonlinear.

This paper is just a first attempt to quantify the relationships between functional traits and a generalized gradient of soil fertility that applies at the scale of communities. Although these results would need to be scaled up to larger scales and more complex ecosystems, it would certainly be also possible to (i) improve the measurement model of generalized fertility by using more or other indicator species having stronger responses to $F_{G}$ and (ii) quantify the relationships involving other functional traits that could be expected to vary with a gradient of soil fertility.

\section{Acknowledgements}

This research was funded by the Natural Sciences and Engineering Research Council of Canada. We thank Didier Labarre and Xavier Lamontagne for help in the experimental setup, and the technical staff of the INRA experimental station at La Fage for access to facilities. The experimental facilities 
« Terrain d'expériences » and « Plateforme d'Analyses Chimiques en Ecologie” from the CeMEB LabEx (an ANR "Investissements d'avenir" program (ANR-10-LABX-04-01)) have contributed to this work. We thank Virginie Pons for her help in laboratory analysis.

\section{Supporting Information}

Additional supporting information may be found online at: [link to be added in production]

\section{Open Research}

All code and data are available in the Supporting Information within Data S1, with a simplified version in Appendix S1: Section S1.

\section{References:}

Bates, D., M. Maechler, B. Bolker, and S. Walker. 2015. Fitting Linear Mixed-Effects Models Using lme4. Journal of Statistical Software, 67:1-48.

Ben-Dor, E., and A. Banin. 1989. Determination of organic matter content in arid-zone soils using a simple "loss-on-ignition" method. Communications in Soil Science and plant Analysis 20:15-16.

Bernard-Verdier, M., M.-L. Navas, M. Vellend, C. Violle, A. Fayolle, and E. Garnier. 2012. Community assembly along a soil depth gradient: contrasting patterns of plant trait convergence and divergence in a Mediterranean rangeland. Journal of Ecology 100:1422-1433.

Brewster, J. L., K. K. S. Bhat, and P. H. Nye. 1976. The possibility of predicting solute uptake and plant growth response from independently measured soil and plant characteristics. V. The growth and phosphorus uptake of rape in soil at a range of phosphorus concentrations and a comparison of results with the predictions of a simulation model. Plant and Soil 44:295-328. 
Chapin III, F. S. 1980. The mineral nutrition of wild plants. Annual Revised Ecology Systems $11: 233-260$.

Chapin III, F. S., P. M. Vitousek, and K. van Cleve. 1986. The Nature of Nutrient Limitation in Plant Communities. The American Naturalist, 127:48-58.

Chapin III, F. S., K. Autumn, and F. Pugnaire. 1993. Evolution of suites of traits in response to environmental stress. The American Naturalist S78-S92.

Chollet, S., S. Rambal, A. Fayolle, D. Hubert, D. Foulquié, and E. Garnier. 2014. Combined effects of climate, resource availability, and plant traits on biomass produced in a Mediterranean rangeland. Ecology 95:737-748.

Cingolani, A. M., G. Posse, and M. B. Collantes. 2005. Plant functional traits, herbivore selectivity and response to sheep grazing in Patagonian steppe grasslands. Journal of Applied Ecology 42:50-59.

Craine, J. M., J. Froehle, D. G. Tilman, D. A. Wedin, and F. S. Chapin III. 2001. The relationships among root and leaf traits of 76 grassland species and relative abundance along fertility and disturbance gradients. OIKOS 93:274-285.

Danger, M., T. Daufresne, F. Lucas, S. Pissard, G. Lacroix. 2008. Does Liebig's law of the minimum scale up from species to communities? Oikos 117:1741-1751.

Daou, L. and B. Shipley. 2019. The measurement and quantification of generalized gradients of soil fertility relevant to plant community ecology. Ecology 100(1):e02549. 10.1002/ecy.2549

Daou, L. and B. Shipley. 2020. Simplifying the protocol for the quantification of generalized soil fertility gradients in plant community ecology. Plant and Soil DOI : 10.1007/s11104-020-047294PLSO-D-19-02315R2

Dray, S., and A. B. Dufour. 2007. The ade4 package: implementing the duality diagram for ecologists. Journal of Statistical Software 22:1-20.

Fay, F. A., S. M. Prober, W. S. Harpole, J. M. H. Knops, J. D. Bakker, E. T. Borer, E. M. Lind, S. A. MacDougall, E. W. Seabloom, P. D. Wragg, P. B. Adler, D. M. Blumenthal, Y. M. Buckley, C. Chu, E. E. Cleland, S. L. Collins, K. F. Davies, G. Du, X. Feng, J. Firn, D. S. Gruner, N. Hagenah, Y. 
Hautier, R. W. Heckman, V. L. Jin, K. P. Kirkman, J. Klein, L. M. Ladwig, Q. Li, R. L. McCulley, B. A. Melbourne, C. E. Mitchell, J. L. Moore, J. W. Morgan, A. C. Risch, M. Schütz, C. J. Stevens, D. A. Wedin, and L. H. Yang. 2015. Grassland productivity limited by multiple nutrients. Nature Plants $1: 1-5$.

Fujita, Y., P. M. van Bodegom, and J.-P. Witte. 2013. Relationships between Nutrient-Related Plant Traits and Combinations of Soil N and P Fertility Measures. PLoS ONE 8(12): e83735. doi:10.1371/journal.pone.0083735

Garnier, E., B. Shipley, C. Roumet, and G. Laurent. 2001. A standardized protocol for the determination of specific leaf area and leaf dry matter content. Functional Ecology 15:688-695.

Garnier, E., J. Cortez, G. Billès, M.-L. Navas, C. Roumet, M. Debussche, G. Laurent, A. Blanchard, D. Aubry, A. Bellmann, C. Neill, and J.-P. Toussaint. 2004. Plant functional markers capture ecosystem properties during secondary succession. Ecology 85:2630-2637.

Garnier, E., M.-L. Navas, and K. Grigulis. 2016. Plant Functional Diversity - Organism traits, community structure, and ecosystem properties (Oxford Univ. Press, 2016).

Garnier, E., A. Fayolle, M.-L. Navas C. Damgaard, P. Cruz, D. Hubert, J. Richarte, P. Autran, C. Leurent, and C. Violle. 2018. Plant demographic and functional responses to management intensification: A long-term study in a Mediterranean rangeland. Journal of Ecology 106:1363-1376.

Gelman, A., Y.-S. Su, M. Yajima, J. Hill, M. G. Pittau, J. Kerman, T. Zheng, and V. Dorie. 2007.

Functions to accompany A. Gelman and J. Hill, Data Analysis Using Regression and Multilevel/hierarchical Models, Cambridge University Press, 2007.

Grime, J. P. 1977. Evidence for the existence of three primary strategies in plants and its relevance to ecological and evolutionary theory. The American Naturalist 111:1169-1194.

Grime, J. P. 1979. Plant strategies and vegetation processes. John Wiley and Sons, New York, New York, USA. 222p.

Grime, J. P. 2001. Plant Strategies, Vegetation Processes, and Ecosystem Properties (2nd edition). John Wiley \& Sons, Chichester. 456p.

This article is protected by copyright. All rights reserved 
Hodgson, J. G., G. Montserrat-Martí, M. Charles, G. Jones, P. Wilson, B. Shipley, M. Sharafi, B. E. L. Cerabolini, J. H. C. Cornelissen, S. R. Bogard, A. Band P. Castro-Díez, J. Guerrero-Campo, M. C. Pérez-Rontomé, G. Carter, A. Hynd, A., Romo-Díez, L. de Torres Espuny, and F. Royo Pla. 2011. Is leaf dry matter content a better predictor of soil fertility than specific leaf area? Annals of Botany 108:1337-1345.

Jager, M. M., S. J. Richardson, P. J. Bellingham, M. J. Clearwater, and D. C. Laughlin. 2015. Soil fertility induces coordinated responses of multiple independent functional traits. Journal of Ecology 103:374-385.

Laughlin, D. C., and D. E. Laughlin. 2013. Advances in modeling trait-based plant community assembly. Trends in Plant Science 18:584-593.

Laughlin, D. C., S. J. Richardson, E. F. Wright, and P. J. Bellingham. 2015. Environmental Filtering and Positive Plant Litter Feedback Simultaneously Explain Correlations Between Leaf Traits and Soil Fertility. Ecosystems 18:1269-1280.

Lemaire, G., and F. Gastal. 1997. N uptake and distribution in plant canopies, Diagnosis on the Nitrogen Status in Crops (ed. G. Lemaire). pp. 3-43. Springer-Verlag, Heidelberg.

Li, Y., and B. Shipley. 2017. An experimental test of CSR theory using a globally calibrated ordination method. PLoS ONE 12(4): e0175404.

Liu, X., N. G. Swenson, J. S. Wright, L. Zhang, K. Song, Y. Du, J. Zhang, X. Mi, H. Ren, and K. Ma. 2012. Covariation in Plant Functional Traits and Soil Fertility within Two Species-Rich Forests. PLoS ONE 7(4).

Louault, F., J. Pottier, P. Note, D. Vile, J.-F. Soussana, and P. Carrère. 2017. Complex plant community responses to modifications of disturbance and nutrient availability in productive permanent grasslands. Journal of Vegetation Science 28:538-549.

Maire, V., I. J. Wright, I. C. Prentice, N. H. Batjes, R. Bhaskar, P. M. van Bodegom, W. K. Cornwell, D. Ellsworth, U. Niinemets, A. Ordonez, P. B. Reich, and L. S. Santiago. 2015. Global effects of soil and climate on leaf photosynthetic traits and rates. Global Ecology and Biogeography 24:706-717. Ordoñez, J. C., P. M. van Bodegom, J. M. Witte, I. J. Wright, P. B. Reich, and R. Aerts. 2009. A global study of relationships between leaf traits, climate and soil measures of nutrient fertility. Global Ecology and Biogeography 18:137-149.

This article is protected by copyright. All rights reserved 
Ordoñez, J. C., P. M. van Bodegom J. M. Witte, R. P. Bartholomeus, J. R. van Hal, and R. Aerts. 2010. Plant Strategies in Relation to Resource Supply in Mesic to Wet Environments: Does Theory Mirror Nature. The American Naturalist 175:225-239.

Ordonez, A. and H. Olff. 2013. Do alien plant species profit more from high resource supply than natives? A trait-based analysis. Global Ecology and Biogeography 11:648-658.

Pérez-Ramos, I. M., C. Roumet, P. Cruz, A. Blanchard, P. Autran, E. Garnier. 2012. Evidence for a 'plant community economics spectrum' driven by nutrient and water limitations in a Mediterranean rangeland of southern France. Journal of Ecology 100:1315-1327.

Pierce, S., G. Brusa, I. Vagge, and B.E.L. Cerabolini. 2013. Allocating CSR plant functional types: the use of leaf economics and size traits to classify woody and herbaceous vascular plants. Functional Ecology 27:1002-1010.

Pierce, S., D. Negreiros, B. E. L. Cerabolini, J. Kattge, S. Díaz, M. Kleyer, B. Shipley, S. J. Wright, N. A. Soudzilovskaia, V. G. Onipchenko, P. M. van Bodegom, C. Frenette-Dussault, E. Weiher, B. X. Pinho, J. H. C. Cornelissen, J. P. Grime, K. Thompson, R. Hunt, P. J. Wilson, G. Buffa, O. C. Nyakunga, P. B. Reich, M. Caccianiga, F. Mangili, R. M. Ceriani, A. Luzzaro, G. Brusa, A. Siefert, N. P. U. Barbarosa, F. S. Chapin III, W. K. Cornwell, J. Fang, G. W. Fernandes, E. Garnier, S. Le Stradic, J. Peñuelas, F. P. L. Melo, A. Slaviero, M. Tabarelli, and D. Tampucci. 2017. A global method for calculating plant CSR ecological strategies applied across biomes world-wide. Functional Ecology 31:444-457.

Pontes, L. S. Da, J.-F. Soussana, F. Louault, D. Andueza, and P. Carrère. 2007. Leaf traits affect the above-ground productivity and quality of pasture grasses. Functional Ecology 21:844-853.

R Development Core Team R: a Language and Environment for Statistical Computing 3-900051-07-

0, R Foundation for Statistical Computing, Vienna, Austria (2013)

http://www.R-project.org/

Rosseel, Y. 2012. lavaan: An R Package for Structural Equation Modeling. Journal of Statistical Software 48:1-36. URL http://www.jstatsoft.org/v48/i02/.

This article is protected by copyright. All rights reserved 
Shipley, B., D. Vile, and E. Garnier. 2006. From plant traits to plant communities: a statistical mechanistic approach to biodiversity. Science 314:812-814.

Shipley, B. 2010. From plant traits to vegetation structure. Chance and selection in the assembly of ecological communities. Cambridge Univ. Press, Cambridge UK.

Shipley, B., F. De Bello, J. H. C. Cornelissen, E. Laliberté, D. C. Laughlin, and P. B. Reich. 2016. Reinforcing loose foundation stones in trait-based plant ecology. Oecologia 180:923-931.

Shipley, B., M. Belluau, I. Kühn, N. A. Soudzilovskaia, M. Bahn, J. Penuelas, J., Kattge, L. Sack, J. Cavender-Bares, W. A. Ozinga, B. Blonder, P. M. van Bodegom, P. Manning, T. Hickler, E. Sosinski, V. De Patta Pillar, V., Onipchenko, and P. Poschlod. 2017. Predicting habitat affinities of plant species using commonly measured functional traits. Journal of Vegetation Science 28:1085-1095.

Tilman, D. 1988. Plant strategies and the dynamics and structure of plant communities. Princeton University Press.

Vile, D., B. Shipley, and E. Garnier. 2006. Ecosystem productivity can be predicted from potential relative growth rate and species abundance. Ecology letters 9:1061-1067.

Vitousek, P.M., G. Aplet, D. Turner, and J. J. Lockwood. 1992. The Mauna Loa environmental matrix: foliar and soil nutrients. Oecologia, 89:372-382.

Warton, D. I., B. Shipley, and T. Hastie. 2015. CATS regression - a model-based approach to study trait-based community assembly. Methods in Ecology and Evolution 6:389-398.

Westoby, M. 1999. The LHS strategy scheme in relation to grazing and fire. roceedings of the VIth International Rangeland Congress (eds D. Eldridge \& D. Freudenberger), pp. 893-896. Australian Rangeland Society, Queensland, Australia.

Wood, S.N., N. Pya, and B. Saefken. 2016. Smoothing parameter and model selection for general smooth models. Journal of the American Statistical Association 111, 1548-1575 http://dx.doi. org/10.1080/01621459.2016.1180986.

Wood, S. N. 2017. Generalized additive models. An introduction with R, 2nd edition. CRS Press, NY.

This article is protected by copyright. All rights reserved 
Table 1. Percent of the total variance $\left(\mathrm{r}^{2}\right)$ of each community CMW trait mean (Y, columns) explained by each soil property ( $\mathrm{X}$, rows) using a generalized additive model for the Quebec sites: $\mathrm{Y} \sim \mathrm{s}(\mathrm{X})$. NS: not statistically significant. The soil property explaining the largest proportion of the variance of each community attribute is shown in bold for visual identification.

\begin{tabular}{|c|c|c|c|c|c|c|c|}
\hline & C & $\mathrm{S}$ & $\mathrm{R}$ & $\begin{array}{c}\text { LDMC } \\
\text { (proportion) }\end{array}$ & $\begin{array}{c}\text { SLA } \\
\left(\mathrm{mm}^{2}\right. \\
\mathrm{mg}-1)\end{array}$ & $\begin{array}{c}\text { LA } \\
\left(\mathrm{mm}^{2}\right)\end{array}$ & $\begin{array}{l}\text { Vegetative } \\
\text { height }(\mathrm{cm})\end{array}$ \\
\hline $\begin{array}{c}\mathrm{F}_{\mathrm{G}}(\mathrm{RGR}, \text { intact } \\
\text { cores })\end{array}$ & 0.05 & NS & $<0.01$ & NS & NS & NS & 0.31 \\
\hline $\begin{array}{c}\mathrm{F}_{\mathrm{G}} \text { (final mass, } \\
\text { intact cores) }\end{array}$ & 0.03 & NS & NS & NS & NS & NS & 0.32 \\
\hline $\begin{array}{c}\mathrm{F}_{\mathrm{G}}(\mathrm{RGR}, \text { sieved } \\
\text { soil })\end{array}$ & 0.07 & 0.42 & 0.4 & 0.31 & 0.39 & NS & 0.34 \\
\hline $\begin{array}{c}\mathrm{F}_{\mathrm{G}} \text { (final mass, } \\
\text { sieved soil) }\end{array}$ & NS & 0.48 & 0.45 & 0.36 & 0.45 & NS & 0.16 \\
\hline NO3- & 0.1 & 0.16 & 0.17 & 0.12 & 0.12 & NS & 0.11 \\
\hline$P$ & 0.08 & 0.12 & 0.12 & 0.14 & 0.16 & NS & NS \\
\hline K & 0.06 & 0.01 & 0.01 & 0.07 & NS & NS & NS \\
\hline Organic matter & 0.06 & NS & NS & 0.01 & NS & NS & 0.03 \\
\hline
\end{tabular}


Figure captions

Figure 1. Generalized additive models using cubic regression splines and a smoothing factor $\mathrm{k}$ $=6$ were used to study the relationships between $\mathrm{F}_{\mathrm{G}}$ calculated using final BM in sieved soil and the community-weighed means (CWM) of S and R-scores in Grime's triangle (a,b), and height (c) of 21 sites in Quebec. All relationships are significant and dashed lines represent the confidence interval. Units of $F_{G}$ were defined such as a unit value of $F_{G}$ indicates a soil inducing a wheat ln biomass $(B M)$ of $1 \ln (\mathrm{mg})$ above the average $\ln (\mathrm{BM})$ of wheat while a negative value indicates a wheat $\ln (\mathrm{BM})$ of 1 unit below the average. Generalized fertility $B M: F_{G}$ calculated from $\ln (B M)$ in sieved soils (average $=4.09 \mathrm{mg})$.

Figure 2. Generalized additive models using cubic regression splines and a smoothing factor $\mathrm{k}$ $=6$ were used to study the relationships between $\mathrm{F}_{\mathrm{G}}$ calculated using final BM in sieved soil and the community-weighed means (CWM) of leaf dry matter content (a) and specific leaf area (c) and $\mathrm{F}_{\mathrm{G}}$ calculated using RGR in sieved soil and the CWM of leaf dry matter content (b) and specific leaf area (d) of 21 sites in Quebec (open circles). The colored points represent 7 sites of the south of France. All relationships are significant and dashed lines represent the confidence interval. Units of $F_{G}$ were defined such as a unit value of $F_{G}$ indicates a soil inducing a wheat relative growth rate (RGR) or ln biomass (BM) of respectively $1 \mathrm{mg} \mathrm{g}^{-1} \mathrm{~d}^{-1}$ or $1 \ln (\mathrm{mg})$ above the average RGR or $\ln (\mathrm{BM})$ of wheat while a negative value indicates a wheat RGR or $\ln (\mathrm{BM})$ of 1 unit below the average. Generalized fertility RGR: $F_{G}$ calculated from RGR in sieved soil (average $=80.72 \mathrm{mg} \mathrm{g} \mathrm{g}^{-1} \mathrm{~d}^{-1}$ ); Generalized fertility BM: $F_{G}$ calculated from $\ln (B M)$ in sieved soils (average $=4.09 \mathrm{mg}$ ).

This article is protected by copyright. All rights reserved 


\section{Sieved soils}
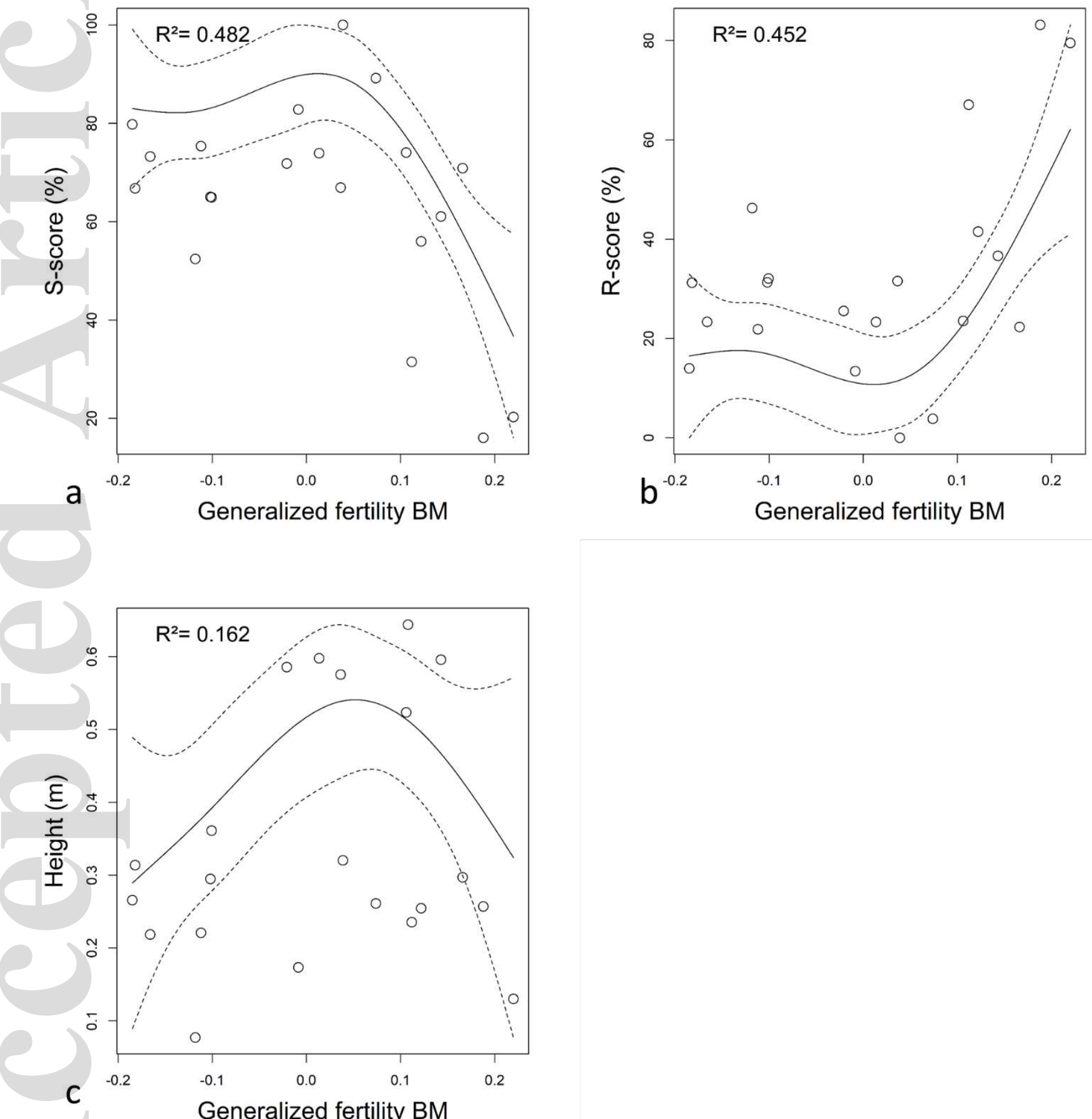

1 Figure 1

This article is protected by copyright. All rights reserved 


\section{Sieved soils}
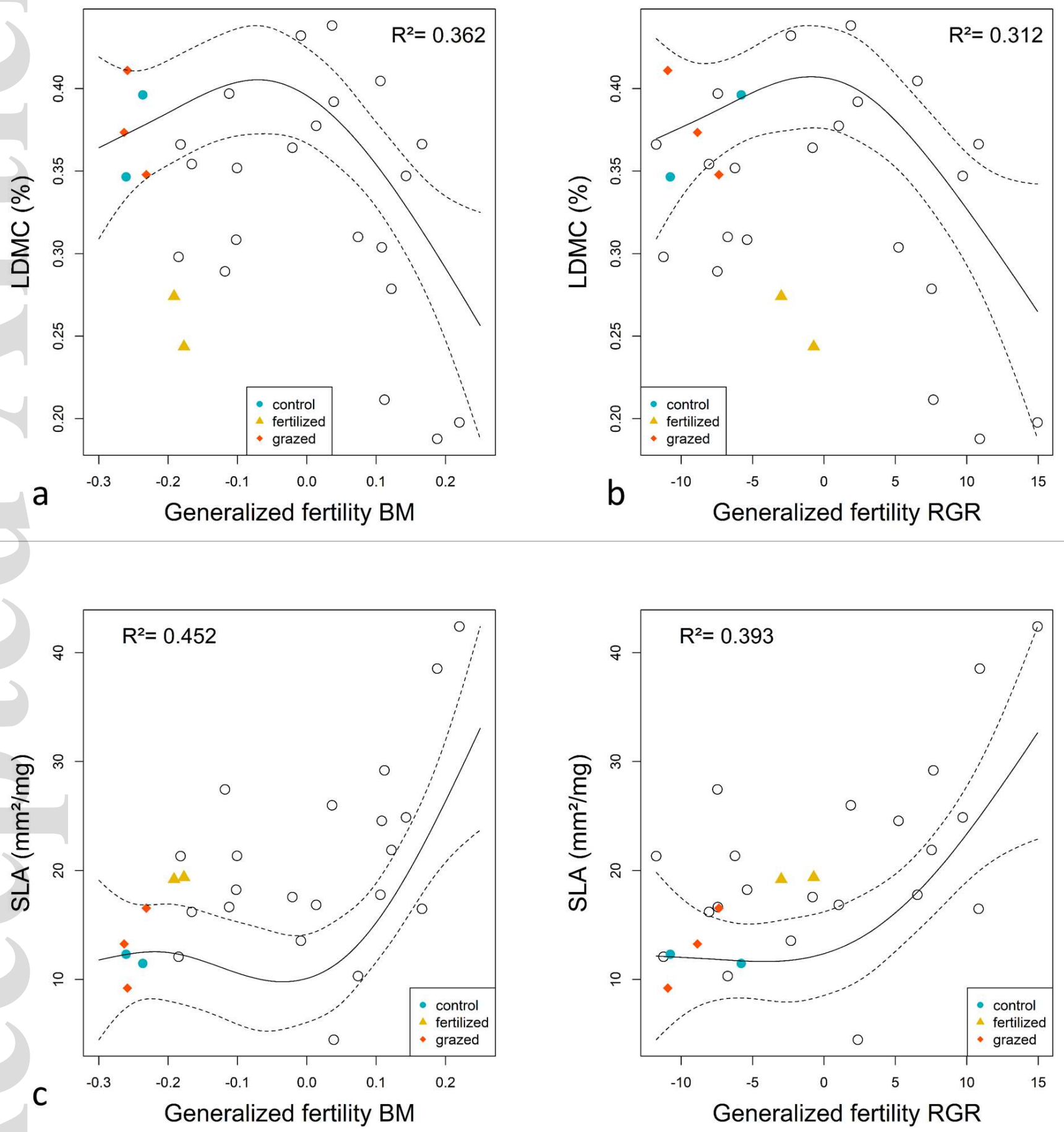

1 Figure 2

This article is protected by copyright. All rights reserved 